\title{
Intravitreal bevacizumab combined with plaque brachytherapy reduces melanoma tumor volume and enhances resolution of exudative detachment
}

This article was published in the following Dove Press journal:

Clinical Ophthalmology

21 January 2013

Number of times this article has been viewed

\author{
Samuel K Houston' \\ Nisha V Shah' \\ Christina Decatur ${ }^{\prime}$ \\ Marcela Lonngi' \\ William Feuer' \\ Arnold M Markoe 2 \\ Timothy G Murray ${ }^{1-3}$ \\ 'Department of Ophthalmology, \\ ${ }^{2}$ Department of Radiation Oncology, \\ Bascom Palmer Eye Institute, \\ University of Miami Miller School \\ of Medicine, Miami, FL, ${ }^{3}$ Murray \\ Ocular Oncology and Retina, Miami, \\ FL, USA
}

Background: The purpose of this study was to evaluate intravitreal bevacizumab as an adjuvant treatment to plaque brachytherapy in the treatment of choroidal melanoma.

Methods: This was a retrospective, consecutive study of 124 patients treated from 2007 to 2009 for choroidal melanoma with plaque brachytherapy. Patients were treated with I-125 plaque brachytherapy with $2 \mathrm{~mm}$ margins and 85 Gy to the tumor apex. Consecutive patients were injected intravitreally with $2.5 \mathrm{mg} / 0.1 \mathrm{~mL}$ bevacizumab at a site away from the primary tumor and immediately following plaque removal. Choroidal melanomas were observed using indirect ophthalmoscopy, wide-angle photography, and ultrasound. The main outcome measures were tumor volume, resolution of exudative retinal detachment, and visual acuity.

Results: One hundred and twenty-four patients met our inclusion criteria and were included in the analysis. The mean patient age was 65.7 years, and the mean apical tumor height was $4.0 \pm 2.7 \mathrm{~mm}$ and basal diameter was $12.7 \pm 3.0 \mathrm{~mm}$. Mean follow-up was 24 months. Prior to treatment, $100 \%$ of tumors had exudative retinal detachment, and pretreatment visual acuity was 20/55 (median 20/40). Tumor control was $100 \%$, metastasis was $0 \%$ at last follow-up, and $89.8 \%$ had complete resolution of exudative retinal detachment, with a mean time to resolution of 3.36 months. At one month, $43 \%$ had complete resolution of exudative retinal detachment, which increased to $73 \%$ at 4 months. Visual acuity was 20/62 (median 20/40) at 4 months, with stabilization to 20/57 (median 20/40) at 8 months, 20/56 (median 20/30) at 12 months, and 20/68 (median 20/50) at 24 months. Tumor volume following combined therapy was shown to be reduced by $22.2 \%$ at 3 months, $28.9 \%$ at 6 months, $39.3 \%$ at 12 months, and $52.2 \%$ at 24 months (all $P<0.001$ ). All patients tolerated the procedure well without systemic side effects.

Conclusion: Intravitreal bevacizumab may be used as an adjuvant agent following plaque brachytherapy. Treated choroidal melanomas show reduction in tumor volume as well as resolution of exudative retinal detachments.

Keywords: choroidal melanoma, brachytherapy, Avastin (bevacizumab), retinal detachment

\section{Introduction}

The Collaborative Ocular Melanoma Study was a randomized clinical trial investigating the use of plaque brachytherapy versus enucleation for medium-sized (apical height 2.5-10.0 mm and basal diameter $\leq 16.0 \mathrm{~mm}$ ) choroidal melanoma. ${ }^{1} \mathrm{I}-125$ plaques were utilized in the Collaborative Ocular Melanoma Study trial, with standard protocol utilizing a plaque covering the entire tumor as well as $2-3 \mathrm{~mm}$ past the margins. Initial 5-year follow-up showed no statistically significant difference in survival between the two modalities, ie, findings that paved the way for widespread adoption of globesalvaging plaque brachytherapy for primary treatment of choroidal melanoma. ${ }^{1}$ Twelveyear results have confirmed these findings regarding survival, with melanoma-specific
Correspondence: Timothy G Murray Murray Ocular Oncology and Retina, 6705 Red Road, Suite 412, Miami, Florida 33143, USA

Tel +l 3054877470

Email tmurray@murraymd.com 
death rates of $21 \%$ and $17 \%$ for plaque brachytherapy and enucleation, respectively. ${ }^{5}$ Local tumor control at 5 years for plaque brachytherapy was $89.7 \%(583 / 650),{ }^{2}$ with other groups reporting individual control rates of $91 \%-96 \%$. ${ }^{6,7}$ The risk of metastasis has been shown to be higher for tumors that fail local treatment. ${ }^{2}$ Karlsson et $\mathrm{al}^{8}$ showed that the risk of metastasis at 5 years following local tumor recurrence was $42 \%$ versus $18 \%$ without failure. ${ }^{9}$ Therefore, ensuring the success of primary treatment is of the utmost importance. To improve local tumor control, intraoperative ultrasound has been recommended during plaque placement to confirm adequate plaque position and identify misplacement or plaque tilt. ${ }^{10}$ In addition, combined treatments have been investigated to enhance local tumor control, decrease treatment-related morbidity, and improve the therapeutic window to expand current treatment to small, large, and juxtapapillary tumors. These latter groups were excluded from the Collaborative Ocular Melanoma Study for plaque brachytherapy.

Combined treatments have included the use of transpupillary thermotherapy as an adjuvant to brachytherapy, ${ }^{11,12}$ with Shields et $\mathrm{al}^{11}$ reporting rates of local tumor recurrence as low as $2 \%-3 \%$. Combined treatments have also been investigated for large melanomas, ${ }^{13}$ as well as for juxtapapillary tumors. ${ }^{14}$ Other combined treatments have included photodynamic therapy, ${ }^{15}$ periocular triamcinolone acetonide, ${ }^{16}$ and local resection. ${ }^{17,18}$ More recently, systemic and local treatment with angiogenic inhibitors have been investigated. ${ }^{19,20}$

In this study, we analyzed 124 patients with choroidal melanoma who were treated with I-125 plaque brachytherapy combined with intravitreal bevacizumab following plaque removal. We evaluated the clinical response of patients over time with regard to tumor reduction, resolution of exudative retinal detachment, and visual function.

\section{Materials and methods}

\section{Patients}

This was a consecutive study of 124 patients treated from 2007 to 2009 for choroidal melanoma using plaque brachytherapy. Data were collected retrospectively. Patients were treated by I-125 plaque brachytherapy with $2 \mathrm{~mm}$ margins and $85 \mathrm{~Gy}$ to the tumor apex. Consecutive patients were injected intravitreally with $2.5 \mathrm{mg} / 0.1 \mathrm{~mL}$ bevacizumab at a site away from the primary tumor and immediately following plaque removal. Choroidal melanomas were observed using indirect ophthalmoscopy, wide-angle photography, and ultrasound. Tumor volume measurements were made based on a hemiellipsoid model, where volume $(V)=2 \pi / 3\left(\left[D_{1}+D_{2}\right] / 4\right)^{2} * H$. Inclusion criteria included choroidal melanoma with a minimum 6-month follow-up. Patients were evaluated with spectral-domain optical coherence tomography, indirect ophthalmoscopy, and ultrasound at 2-3-month intervals following plaque removal.

\section{Plaque brachytherapy procedure}

All patients presenting with posterior uveal melanoma underwent placement with I-125 radioactive plaque using standard surgical techniques. After initial preparation, draping, and anesthesia, patients underwent 360 degree conjunctival peritomy. The four rectus muscles were isolated with muscle hooks and 2-0 Ethibond sutures, followed by transpupillary transillumination of the globe to mark the location of the tumor. If surgically indicated for proper plaque placement, one of the rectus muscles was disinserted in order to make room for the plaque. A standard Collaborative Ocular Melanoma Study plaque was used and consisted of a silastic implant with I-125 seed grooves placed into a gold-backed shield. I-125 plaque seeds designed to deliver 85 Gy to the tumor apex were used in all cases. ${ }^{3,4}$ After the plaque was brought into the surgical field, 5-0 Nylon sutures were used to secure the plaque to the sclera, followed by determination of proper positioning with intraoperative ultrasound by either the surgeon (TGM) or a registered diagnostic medical ultrasonographer using a contact B-scan instrument (Ophthascan S; Alcon Surgical Inc, Irvine, CA, or Innovative Imaging Inc, Sacramento, CA). Echographic studies were performed to view the tumor both longitudinally and transversely in order to verify plaque location relative to the tumor. If removed, rectus muscles were reattached, and the conjunctiva was closed. The operated eye was patched and shielded with a lead shield, and plaque was removed after an average of 72 hours.

\section{Bevacizumab injections}

Patients were treated with $2.5 \mathrm{mg} / 0.1 \mathrm{~mL}$ intravitreal bevacizumab at the time of plaque removal. Briefly, following the removal of the episcleral plaque, any rectus muscles were reattached and the conjunctiva were closed. Following closure, a caliper was used to measure 3.5-3.9 mm posterior to the limbus depending on lens status $(3.5 \mathrm{~mm}$ for pseudophakia, $3.9 \mathrm{~mm}$ for phakia). At the conclusion of surgery, patients were injected intravitreally with $0.1 \mathrm{~mL}$ bevacizumab.

\section{Results}

A total of 139 patients with choroidal melanoma were treated with combined plaque brachytherapy and intravitreal bevacizumab. Fifteen cases were excluded secondary to 
lack of documented follow-up, resulting in 124 patients for analysis. The study group comprised 64 men (52\%) and 60 women (48\%). Mean patient age was 65.7 (28-90) years. Pretreatment mean apical tumor height was $4.0 \pm 2.7$ (range 1.0-12.9) $\mathrm{mm}$ and basal diameter was $12.7 \pm 3.0$ (range 3.5-18.0) $\mathrm{mm}$. Mean follow-up was 24 (range 6-42) months (Table 1). Tumor burden was shown to be reduced by $22.2 \%$ at 3 months, $28.9 \%$ at 6 months, $39.3 \%$ at 12 months, and $52.2 \%$ at 24 months (all $P<0.001$, Table 2). Prior to treatment, $100 \%$ of tumors had exudative retinal detachments, pretreatment visual acuity was 20/55 (median 20/40); and 89.8\% had complete resolution of exudative retinal detachment, with a mean time to resolution of 3.36 months. At one month, $43 \%$ had complete resolution of exudative retinal detachment, which increased to $73 \%$ at 4 months (Table 3). By 4 months post-treatment, mean visual acuity decreased to 20/62 (median of 20/40), but this stabilized to $20 / 57$ (median of 20/40) at 8 months. Mean visual acuity at 12 months was 20/56 (median of 20/30), which decreased to $20 / 68$ (median of 20/50) at 24 months (Table 4). Of 124 patients, 23 patients $(18.5 \%)$ had vision of $20 / 200$ or worse, with $81.5 \%$ maintaining ambulatory vision. Tumor control was $100 \%$ and metastasis was $0 \%$ at last follow-up. Patients tolerated the procedure well without systemic side effects and minimal local side effects.

\section{Discussion}

In this study, we analyzed the effect of adjuvant treatment with anti-vascular endothelial growth factor (VEGF) agents following I-125 plaque brachytherapy in 124 patients with choroidal melanoma. All patients were treated with 85 Gy to the tumor apex and were then treated with intravitreal bevacizumab $2.5 \mathrm{mg} / 0.01 \mathrm{~mL}$ at the time of plaque removal. At 24 months, local tumor control was 100\%, with no metastases. We consider the timing of treatment

Table I Patient demographics

\begin{tabular}{ll}
\hline Patient demographics & \\
\hline Total plaqued eyes & $\mathrm{n}=139$ \\
$\begin{array}{l}\text { Total plaqued with minimum } \\
\text { of } 6 \text { months follow-up }\end{array}$ & $\mathrm{n}=124$ \\
Mean follow-up & 24 months \\
Males & $64(52 \%)$ \\
Females & $60(48 \%)$ \\
Mean patient age & 65.7 years \\
Tumor characteristics & \\
Apical height & $4.0 \mathrm{~mm}(\mathrm{SD} 2.7)$ \\
Basal diameter & $12.7 \mathrm{~mm}$ (SD 3.0) \\
Exudative detachment & $124 / \mathrm{I} 24$ (I00\%) \\
\hline
\end{tabular}

Abbreviation: SD, standard deviation.
Table 2 Percent reduction in tumor burden

\begin{tabular}{ll}
\hline Time & $\begin{array}{l}\text { Tumor } \\
\text { reduction }\end{array}$ \\
\hline 3 months & $22.2 \%($ SD 26.I) \\
6 months & $28.9 \%(S D 29.6)$ \\
I 2 months & $39.3 \%(S D 28 . I)$ \\
24 months & $52.2 \%$ (SD 28.4) \\
$P<0.00$ I for all values from baseline & \\
\hline
\end{tabular}

Abbreviation: SD, standard deviation.

with anti-VEGF agents to be an important consideration prior to this adjuvant treatment. VEGF has been shown to be elevated in vitreous and aqueous samples in eyes harboring melanoma. VEGF levels have also been found to have a positive association with increased apical height and basal diameter. ${ }^{21}$ Of note, eyes previously treated with plaque brachytherapy had the highest concentrations of VEGF. $^{22}$ Although there is some evidence to suggest that antiangiogenic agents may serve as a radiosensitizer, we have investigated the role of hypoxia following these agents in animal models. Our laboratory has shown that $\mathrm{LH}_{\mathrm{BETA}} \mathrm{T}_{\mathrm{AG}}$ retinoblastoma tumors have significant areas of hypoxia which may be transiently increased following treatment with angiogenic inhibitors. ${ }^{23}$ Hypoxic cells have been shown to be resistant to radiation therapy, so we propose that treatment with anti-VEGF agents prior to plaque brachytherapy may hinder the radiation effect on tumor cells. As a result, we elected to utilize adjuvant bevacizumab after full treatment with plaque brachytherapy.

Following treatment with plaque brachytherapy, choroidal melanomas may transiently increase in size due to edema, inflammation, or necrosis, ${ }^{24}$ followed by reduction or stabilization in tumor size over time. Recurrence or unresponsiveness following plaque brachytherapy may indicate failure of local tumor control. Abramson et $\mathrm{al}^{25}$ showed a $12 \%$ tumor reduction ( $88 \%$ residual tumor burden) at 6 months following plaque brachytherapy, which increased to a $24 \%$ reduction $(76 \%$ residual tumor burden) at 12 months. Following combined treatment with I-125 plaque brachytherapy and intravitreal bevacizumab, there was a significant decrease in tumor burden at all time

Table 3 Percent reduction in exudative retinal detachment (ERD)

\begin{tabular}{ll}
\hline Time & $\begin{array}{l}\text { Percent } \\
\text { resolution }\end{array}$ \\
\hline I month & $43 \%$ \\
4 months & $73 \%$ \\
6 months & $84 \%$ \\
12 months & $89.8 \%$ \\
Mean time to resolution & 3.36 months \\
\hline
\end{tabular}


Table 4 Visual acuity

\begin{tabular}{ll}
\hline Time & Visual acuity \\
\hline Baseline & $20 / 55($ median 20/40) \\
4 months & $20 / 62($ median 20/40) \\
8 months & $20 / 57($ median 20/40) \\
12 months & $20 / 56($ median 20/30) \\
24 months & $20 / 68($ median 20/50) \\
$P<0.25$ for all values from baseline & \\
\hline
\end{tabular}

points compared with baseline $(P<0.001)$. As early as 3 months, tumors already showed a $22.2 \%$ reduction in size, with a $28.9 \%$ reduction at 6 months. Tumor volume reduction continued to decrease at 12 months and 24 months, by 39.3\% and $52.2 \%$, respectively (Figure 1). Like other solid tumors, choroidal melanomas have an intrinsic vasculature that provides necessary nutrients and waste removal to highly proliferating neoplastic cells. Treatment with angiogenic inhibitors may target this intrinsic vasculature, thus resulting in enhanced tumor reduction when combined with plaque brachytherapy.

Exudative retinal detachments have been shown to be a common finding in choroidal melanomas, with an incidence ranging from $53 \%-75 \%{ }^{2,26,27}$ Exudative retinal detachments are the primary cause of early vision loss, with chronic detachments leading to photoreceptor loss and atrophy contributing to longterm changes as well. In addition, resolution of exudative retinal detachment may be an early sign of clinical response to treatment, with persistent exudative retinal detachment being associated with continued tumor activity. Kivela et al ${ }^{27}$ have shown that exudative retinal detachment is associated with microvascular loops and networks on histopathologic analysis. Clinical exudative retinal detachment predicted poor survival; however, when adjusted for tumor size and vasculogenic mimicry patterns, exudative retinal detachment was not associated with survival.

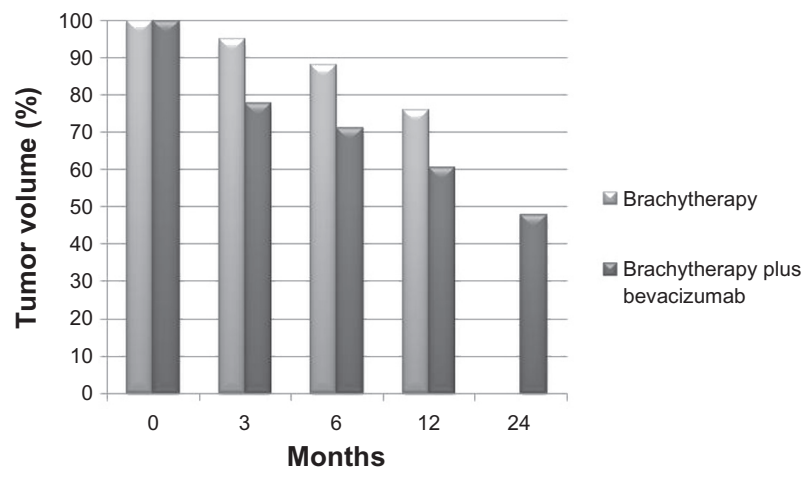

Figure I Tumor burden with brachytherapy alone (Abramson et $\mathrm{a}^{25}$ ) compared with combined treatment with plaque brachytherapy and intravitreal bevacizumab.

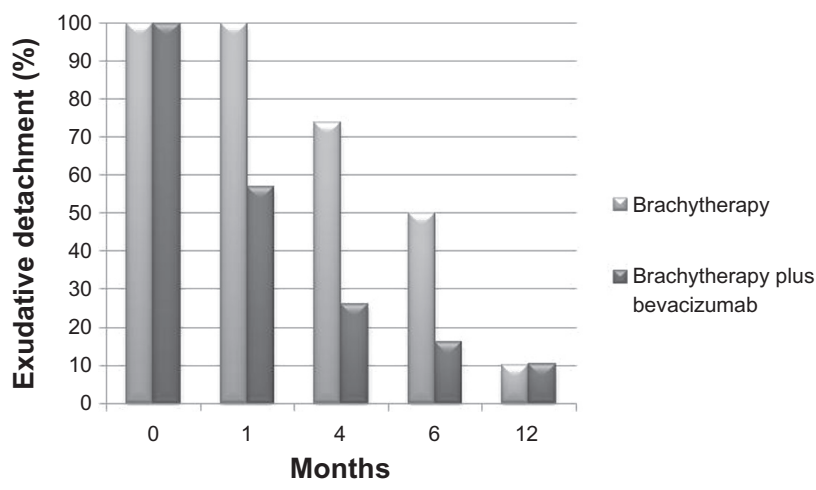

Figure 2 Exudative retinal detachment compared to prior studies ${ }^{26}$ showing enhanced rate of resolution with combined plaque brachytherapy and intravitreal bevacizumab.

Harbour et $\mathrm{a}^{26}$ have shown the natural history of tumor exudation following treatment with plaque brachytherapy. By 3.9 months, $25 \%$ exhibited resolution, increasing to $50 \%$ by 4.7 months, $83 \%$ by 9 months, and $90 \%$ by 12 months. The average time to resolution of exudative detachment was found to be 5.6 months. With combined treatment in the current study, average time to resolution of exudative retinal detachment was 3.36 months, which is greater than 2 months earlier than in prior reports. Additionally, after one month of combined treatment, $43 \%$ of patients had resolution of exudative retinal detachment. This increased to $73 \%$ by 4 months, and to $90 \%$ by 12 months. Our results show that although resolution rates approach $90 \%$ for singlemodality (plaque brachytherapy) and combined therapy (plaque + bevacizumab) by 12 months, adjuvant bevacizumab leads to earlier resolution of exudative retinal detachment (Figure 2).

With early and long-term vision changes being associated with photoreceptor loss from chronically detached retina, earlier resolution of subretinal fluid may lead to improved visual outcomes. In the current study, mean visual acuity at baseline was found to be 20/55 (median 20/40). Four months following treatment, visual acuity dropped to 20/62 (median 20/40), followed by improvement back to $20 / 57$ (median 20/40) at 8 months, and 20/56 (median 20/30) at 12 months. Adjuvant treatment may stabilize tumor vasculature following treatment, thus decreasing vascular permeability and tumor vascular activity. With resolution of the subretinal fluid, visual acuity lags behind the restoration of retinal architecture, with vision stabilized at later time points. This early visual acuity stabilization lends to later decreases secondary to effects of radiation retinopathy, with vision decreased to 20/68 (median 20/50) at 24 months. 
Strengths of the current study include a large, consecutive case series of a proposed combined treatment for uveal melanoma. Although case reports highlight the potential use of angiogenic inhibitors in primary and treatment-related complications for uveal melanoma, this is the first study investigating this combined treatment, to the authors' knowledge. Weaknesses of the study include its lack of a comparative control, randomization, and retrospective nature.

This study reports on the potential utility of intravitreal angiogenic inhibitors when used in combination with plaque brachytherapy. Combined therapy may help to minimize tumor-related complications, such as exudative retinal detachment, as well as reduce tumor volume. Long-term follow-up is needed to determine the effect of combined therapy on local tumor control, metastasis, and survival. Further research is needed on the effects of tumor and treatment-related complications, as well as the potential use of combined treatments to combat these vision-threatening effects.

The current study reports on the use of adjuvant intravitreal bevacizumab following the treatment of choroidal melanoma with I-125 plaque brachytherapy. Combined treatment resulted in enhanced tumor volume reduction, earlier resolution of subretinal fluid associated with exudative retinal detachments, and stabilization of visual acuity. Adjuvant intravitreal bevacizumab may be used in the treatment of choroidal melanoma when used after treatment with plaque brachytherapy.

\section{Disclosure}

None of the authors have proprietary or financial interest to disclose in this work.

\section{References}

1. Diener-West M, Earle JD, Fine SL, et al. The COMS randomized trial of iodine 125 brachytherapy for choroidal melanoma, III: initial mortality findings. COMS Report No 18. Arch Ophthalmol. 2001;119:969-982.

2. Jampol LM, Moy CS, Murray TG, et al. The COMS randomized trial of iodine 125 brachytherapy for choroidal melanoma: IV. Local treatment failure and enucleation in the first 5 years after brachytherapy. COMS report no 19. Ophthalmology. 2002;109:2197-2206.

3. Nath R, Anderson LL, Luxton G, Weaver KA, Williamson JF, Meigooni AS. Dosimetry of interstitial brachytherapy sources: recommendations of the AAPM Radiation Therapy Committee Task Group No 43. American Association of Physicists in Medicine. Med Phys. 1995;22:209-234.

4. Ray SK, Bhatnagar R, Hartsell WF, Desai GR. Review of eye plaque dosimetry based on AAPM Task Group 43 recommendations. American Association of Physicists in Medicine. Int J Radiat Oncol Biol Phys. 1998;41:701-706.

5. [No authors listed]. The COMS randomized trial of iodine 125 brachytherapy for choroidal melanoma: V. Twelve-year mortality rates and prognostic factors: COMS report No 28. Arch Ophthalmol. 2006;124:1684-1693.
6. Wilson MW, Hungerford JL. Comparison of episcleral plaque and proton beam radiation therapy for the treatment of choroidal melanoma. Ophthalmology. 1999;106:1579-1587.

7. Gunduz K, Shields CL, Shields JA, Cater J, Freire JE, Brady LW. Radiation complications and tumor control after plaque radiotherapy of choroidal melanoma with macular involvement. Am J Ophthalmol. 1999;127:579-589.

8. Karlsson UL, Augsburger JJ, Shields JA, Markoe AM, Brady LW, Woodleigh R. Recurrence of posterior uveal melanoma after 60Co episcleral plaque therapy. Ophthalmology. 1989;96: 382-388.

9. Vrabec TR, Augsburger JJ, Gamel JW, Brady LW, Hernandez C, Woodleigh R. Impact of local tumor relapse on patient survival after cobalt 60 plaque radiotherapy. Ophthalmology. 1991;98: 984-988.

10. Harbour JW, Murray TG, Byrne SF, et al. Intraoperative echographic localization of iodine 125 episcleral radioactive plaques for posterior uveal melanoma. Retina. 1996;16:129-134.

11. Shields CL, Cater J, Shields JA, et al. Combined plaque radiotherapy and transpupillary thermotherapy for choroidal melanoma: tumor control and treatment complications in 270 consecutive patients. Arch Ophthalmol. 2002;120:933-940.

12. Bartlema YM, Oosterhuis JA, Journee-De Korver JG, Tjho-Heslinga RE, Keunen JE. Combined plaque radiotherapy and transpupillary thermotherapy in choroidal melanoma: 5 years' experience. $\mathrm{Br} J$ Ophthalmol. 2003;87:1370-1373.

13. Kreusel KM, Bechrakis N, Riese J, Krause L, Wachtlin J, Foerster MH. Combined brachytherapy and transpupillary thermotherapy for large choroidal melanoma: tumor regression and early complications. Graefes Arch Clin Exp Ophthalmol. 2006;244:1575-1580.

14. Sagoo MS, Shields CL, Mashayekhi A, et al. Plaque radiotherapy for juxtapapillary choroidal melanoma: tumor control in 650 consecutive cases. Ophthalmology. 118:402-407.

15. Barbazetto IA, Lee TC, Rollins IS, Chang S, Abramson DH. Treatment of choroidal melanoma using photodynamic therapy. Am JOphthalmol. 2003;135:898-899.

16. Horgan N, Shields CL, Mashayekhi A, et al. Periocular triamcinolone for prevention of macular edema after iodine 125 plaque radiotherapy of uveal melanoma. Retina. 2008;28:987-995.

17. Garcia-Arumi J, Zapata MA, Balaguer O, Fonollosa A, Boixadera A, Martinez-Castillo V. Endoresection in high posterior choroidal melanomas: long-term outcome. Br J Ophthalmol. 2008;92:1040-1045.

18. Querques G, Bux AV, Iaculli C, Delle Noci N. Local resection versus combined local resection and plaque radiotherapy in the treatment of choroidal melanoma. Eur J Ophthalmol. 2010;20:194-200.

19. Newman H, Finger PT, Chin KJ, Pavlick AC. Systemic bevacizumab (Avastin) for exudative retinal detachment secondary to choroidal melanoma. Eur J Ophthalmol. 2011;21:796-801.

20. Lima BR, Schoenfield LR, Singh AD. The impact of intravitreal bevacizumab therapy on choroidal melanoma. Am J Ophthalmol. 2011;151:323-328. e322.

21. Missotten GS, Notting IC, Schlingemann RO, et al. Vascular endothelial growth factor A in eyes with uveal melanoma. Arch Ophthalmol. 2006;124:1428-1434.

22. Boyd SR, Tan D, Bunce C, et al. Vascular endothelial growth factor is elevated in ocular fluids of eyes harbouring uveal melanoma: identification of a potential therapeutic window. Br J Ophthalmol. 2002;86: $448-452$.

23. Boutrid H, Pina Y, Cebulla CM, et al. Increased hypoxia following vessel targeting in a murine model of retinoblastoma. Invest Ophthalmol Vis Sci. 2009;50:5537-5543

24. Gragoudas ES, Egan KM, Saornil MA, Walsh SM, Albert DM, Seddon JM. The time course of irradiation changes in proton beamtreated uveal melanomas. Ophthalmology. 1993;100:1555-1559.

25. Abramson DH, Servodidio CA, McCormick B, Fass D, Zang E. Changes in height of choroidal melanomas after plaque therapy. Br JOphthalmol. 1990;74:359-362. 
26. Harbour JW, Ahmad S, El-Bash M. Rate of resolution of exudative retinal detachment after plaque radiotherapy for uveal melanoma. Arch Ophthalmol. 2002;120:1463-1469.
27. Kivela T, Eskelin S, Makitie T, Summanen P. Exudative retinal detachment from malignant uveal melanoma: predictors and prognostic significance. Invest Ophthalmol Vis Sci. 2001;42:2085-2093.

\section{Publish your work in this journal}

Clinical Ophthalmology is an international, peer-reviewed journal covering all subspecialties within ophthalmology. Key topics include: Optometry; Visual science; Pharmacology and drug therapy in eye diseases; Basic Sciences; Primary and Secondary eye care; Patient Safety and Quality of Care Improvements. This journal is indexed on
PubMed Central and CAS, and is the official journal of The Society of Clinical Ophthalmology (SCO). The manuscript management system is completely online and includes a very quick and fair peer-review system, which is all easy to use. Visit http://www.dovepress.com/ testimonials.php to read real quotes from published authors. 